\title{
AVALIAÇÃO PATOLÓGICA DO REVESTIMENTO DE FACHADA DE UMA HABITAÇÃO FUNCIONAL
}

\author{
PINTO DANTAS, ANA BEATRIZ \\ Engenheira Civil \\ UNAMA \\ Pará; Brasil \\ unamabeatrizdantas@gmail.com
}

\author{
DA SILVA PEREIRA, MIKE \\ Engenheiro Civil \\ UNAMA \\ Pará; Brasil \\ mspmike@hotmail.com
}

\section{RESUMO}

Manifestações patológicas em revestimentos de fachadas são problemas muito comuns na construção civil, sustentados pelo negligenciamento com as fases que envolvem esse sistema. Diante disso, a presente pesquisa tem por objetivo a realização de um estudo de caso que consiste na avaliação do revestimento de fachada de um bloco de apartamentos localizado em uma vila militar em Belém, o qual possui onze anos de utilização e nenhum histórico de manutenção. Para isso, foram realizadas inspeções visuais e registros fotográficos de todos os panos da fachada, além da avaliação de um dos apartamentos, a fỉm de analisar os efeitos dessas anomalias no interior da edificação. A inspeção interna foi realizada em um apartamento com fachada para o norte, onde há maior incidência do sol, ou seja, com fachada mais exposta à agressividade do meio. Com a câmera comum e câmera termográfica, foram realizadas fotografias dos pontos de umidade encontrados. A avaliação do revestimento de fachada concluiu que as principais anomalias identificadas foram destacamentos das placas cerâmicas e deterioração de juntas. A análise interna, com a utilização da câmera térmica FLIR $®$, modelo $C 2$, mostrou os pontos de umidade e possibilitou uma análise qualitativa das patologias que, em um dos cômodos, coincidia com os pontos de destacamento externo. No outro compartimento, mesmo não havendo destacamento da cerâmica na fachada, a parte interna também apresentou infiltrações em razão das pequenas aberturas nas juntas de movimentação que permitem o escoamento da água, comprovando assim, o elevado grau de deterioração do revestimento externo.

Palavras-chave: Anomalias, Juntas, Inspeção, Destacamento.

\begin{abstract}
Pathological manifestations in facade cladding are very common problems in civil construction, sustained by the neglect in the phases that involve this system. Having this is mind, this research aims to conduct a case study that consists in the pathological evaluation of the facade cladding of an apartment block located in a military village in the city of Belem, which has eleven years of use and no history of maintenance. In this sense, visual inspections and photographic records were made of all the walls of the facade, as well as the evaluation of one of the apartments, in order to analyze the effects of these anomalies inside of the building. The internal inspection was carried out in a northfacing apartment, because it has a higher incidence of sunlight, that is, with a facade more exposed to the aggressiveness of the environment. With the common camera and the thermographic camera, photographs were taken of the moisture points found. The evaluation of the facade cladding concluded that the main anomalies identified were detachment of ceramic tiles and deterioration of joints. The internal analysis, using the FLIR ® thermal camera, model $\mathrm{C} 2$, showed the humidity, and enabled a qualitative analysis of the pathologies that, in one of the rooms, coincided with the points of external detachment coincided with the facade detachment points. In the other compartment, even though there was no detachment of the ceramic on the facade, the internal part showed intense infiltration due to the small openings in the movement joints that allow water to flow, thus proving the high degree of deterioration of the external cladding.
\end{abstract}

Keywords: Anomalies, Joints, Inspection, Detachment. 


\section{INTRODUÇÃO}

O revestimento de fachadas tem uma indubitável importância construtiva, que vai além de aspectos de estética. Segundo Ribeiro e Barros (2010), ele também possui a função de proteção e deve garantir que os agentes externos não interfiram na integridade da edificação e conforto dos moradores, cumprindo adequadamente as funções de vedação e proteção térmica e acústica.

Apesar da necessidade de maior atenção às fases que envolvem os revestimentos de fachadas, esse sistema ainda é muito negligenciado. Roscoe (2008) fala sobre o descaso referente às normas que regulamentam as etapas que envolvem o conjunto revestimento cerâmico, o que consequentemente, contribui com o aumento da incidência de casos de patologia em fachadas.

São vários os fatores que provocam o aparecimento das anomalias nos revestimentos externos. Chaves (2009) afirma que os mais recorrentes são: ausência de um adequado projeto de revestimento de fachadas, falta de mão de obra especializada, falta de fiscalização da etapa de execução e uso de materiais incompatíveis com as condições de uso. A autora ainda afirma que as anomalias mais comuns se manifestam em forma de fissuras e descolamentos.

Além da necessidade de atentar-se às questões que envolvem projeto e execução de serviços, a edificação também requer cuidados referentes à sua utilização. Carvalho (2017) aborda sobre a necessidade de manutenção das edificações tanto corretiva como preventiva, a fim de fazer com que os elementos constituintes exerçam satisfatoriamente a função para a qual foram planejados.

A presente pesquisa tem por objetivo avaliar o revestimento de fachada de uma habitação funcional em Belém por meio da sistematização das anomalias observadas em todos os panos da fachada, assim como, seus efeitos no interior da edificação em um dos apartamentos do bloco avaliado, utilizando a inspeção visual e realizando-se o registro fotográfico. Além disso, apresenta-se a análise dos pontos de umidade encontrados na parte interna, com o auxílio da câmera termográfica.

\section{REFERENCIAL TEÓRICO}

\subsection{Patologia em revestimentos de fachadas}

A grande incidência de casos de patologias em revestimentos cerâmicos de fachadas permanece presente mesmo diante das tecnologias desenvolvidas nos últimos anos no setor da construção (MEDEIROS E SABBATINI, 1999). Embora haja estudos bem desenvolvidos na área, a negligência por parte dos responsáveis torna esse problema ainda muito comum.

O interesse pelo lucro, principalmente com a economia de recursos e tempo, tem motivado as empresas a deixarem de ser criteriosas com o serviço de revestimento. Terra (2001) afirma que a busca por produzir mais em menos tempo, tem como resultado o aumento da ocorrência de patologias nesse sistema.

\subsection{Origem}

As patologias podem ser originárias de diversos fatores. A partir da avaliação dessas manifestações é possível determinar suas possíveis causas, sendo possível a aplicabilidade de soluções de acordo com sua origem. Pedro et al. (2002) classifica as origens das patologias em quatro tipos:

- Congênitas: São aquelas que se originam na fase de projeto, quando este não está de acordo com as normas ou quando nele há falhas ou ausência de detalhes construtivos importantes para a integridade da fachada.

- Construtivas: Se originam na etapa de execução, quer seja por falta de mão de obra especializada, uso de materiais inadequados, ou por ausência de especificações para a realização dos serviços.

- Adquiridas: Surgem durante a vida útil e estão relacionadas à exposição aos meios agressivos.

- Acidentais: É o tipo mais incomum. São aquelas que surgem quando ocorrem solicitações não previstas sobre o revestimento. 


\subsection{Manifestações patológicas}

As patologias se manifestam nas fachadas conforme sua origem. Antunes (2010) afirma que as formas mais comuns de aparecimento das patologias no sistema de revestimento de fachadas são: descolamento e destacamento de placas cerâmicas, falhas da vedação, fissuras, falhas nas juntas de movimentação e eflorescências.

- Descolamentos

O descolamento acontece quando a placa não adere mais à base, conforme Antunes (2010). É muito comum, e facilita a passagem de água pelo sistema, podendo causar infiltrações no interior da edificação.

\section{- Destacamentos}

Os destacamentos ocorrem posteriormente ao descolamento e consiste na queda da placa do revestimento (ANTUNES 2010). O problema maior são os acidentes que podem ocorrer aos que transitam ao redor da edificação devido essa queda.

\section{- Fissuras}

As fissuras são causadas pelos esforços que acometem o revestimento. Segundo Chaves (2009), as fissuras são o resultado de tensões solicitantes sobre os revestimentos maiores que o esforço resistente das placas, tensões essas, provocadas, em sua maioria, por variações de temperatura e umidade.

- Falhas nas juntas

Fatores como intemperismo e esforços solicitantes adversos podem levar às falhas nas juntas de assentamento, movimentação e dessolidarização em fachadas. Chaves (2009) afirma que essas falhas podem ocorrer devido ao desgaste do material ao decorrer do tempo ou por perda da capacidade de proteger o revestimento exercendo a função de estanqueidade.

\section{- Eflorescência}

A eflorescência é uma manifestação patológica que influencia principalmente na estética. Segundo Lopes (2009), a eflorescência consiste no manchamento do revestimento cerâmico devido o transporte de sais solúveis presentes na argamassa que se tornam evidentes na fachada, com a evaporação da água e cristalização desses sais.

\subsection{Termografia}

A termografia é um tipo de ensaio que vem tomando espaço no setor de patologia das construções, principalmente por ser um modo rápido e não destrutivo. Cortizo (2007, p. 35) define termografia como "a técnica de um método não destrutivo sem contato de identificação visual do gradiente de temperatura superficial de um corpo em condições ambientais".

O ensaio utilizando a tecnologia termográfica pode ser realizado por meio de duas técnicas diferentes. Segundo Cortizo et al. (2008), elas se classificam como passiva e ativa, onde, para a primeira, não se usa estímulo artificial, o transmissor de calor é o próprio sol. Já a segunda, faz-se com o auxílio de um estímulo artificial.

Os ensaios termográficos são simples comparado aos outros de inspeção patológica. Porém, deve-se levar em consideração alguns critérios. Balaras e Argiriou (2002), afirmam que, para as fotos com a câmera térmica, é necessário um tempo mais ameno e ventos pouco intensos. No entanto, os autores afirmam também que quando a realização do ensaio ocorre em áreas internas, você não corre o risco de fatores externos prejudicarem os resultados.

\section{ESTUDO DE CASO}

\subsection{Metodologia}

A avaliação do objeto de estudo foi feita visualmente realizando-se o registro fotográfico das patologias observadas e com análise termográfica dos pontos de umidade no interior de um dos apartamentos do bloco.

Primeiramente, foi realizada a inspeção visual externa do prédio a fim de identificar as patologias presentes em todos os panos da fachada. Após isso, foram feitas fotografias das anomalias encontradas. A inspeção e registro fotográfico foram realizados a dois e cinco metros da fachada, na altura do terreno, com o zoom da câmera sobre as patologias mais 
distantes no revestimento. Para facilitar a inspeção e organização da análise, as fachadas foram divididas em norte, leste, oeste e sul. A Figura 1 apresenta o Norte como parâmetro de localização.

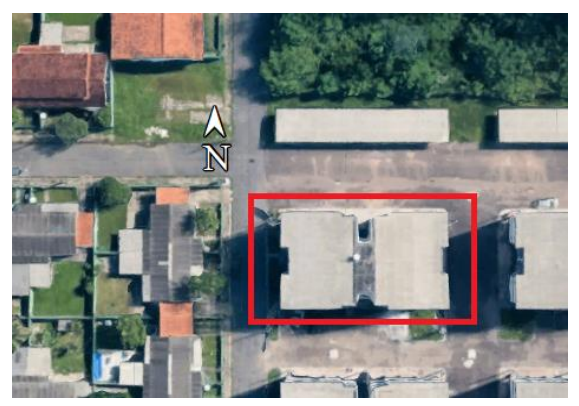

Figura 1: Localização do bloco estudado. Fonte: Google Earth (2020)

Após a inspeção externa, foi realizada a análise dos efeitos das patologias da fachada sobre a área interna da edificação em um dos apartamentos. Repetiu-se o procedimento de avaliação da área externa com a visualização das patologias e registro fotográfico e após isso, foram feitas fotografias por meio da câmera térmica Flir, modelo C2, que possui resolução de 4800 pixels e sensibilidade térmica $<0,10^{\circ} \mathrm{C}$ (FLIR MEDIA, 2014). As fotos foram realizadas a dois e três metros de distância dos pontos observados. O detalhamento dos termogramas foi feito com o auxílio do software FLIR tools, onde foi possível determinar a temperatura de cada ponto.

Todos os registros foram feitos das $16 \mathrm{~h} 30 \mathrm{~min}$ às 17 horas, com o tempo nublado e razoavelmente ameno e temperatura ambiente de $31^{\circ} \mathrm{C}$ (THE WEATHER CHANNEL, 2019).

\subsection{Descrição do objeto de estudo}

O estudo foi realizado em um bloco de apartamentos de uma vila militar em Belém que teve sua inauguração há onze anos, e nesse período, segundo o responsável pelos processos de ocupação e desocupação da habitação, não houve manutenções.

A edificação tem $417,8 \mathrm{~m}^{2}$ de área construída, com entrada ao oeste e térreo composto por pilotis. Possui três pavimentos, com quatro apartamentos em cada andar. É composto por pilares e vigas de concreto armado e alvenaria de vedação com blocos cerâmicos vazados.

O revestimento da fachada é composto por pastilhas cerâmicas nas cores brancas e azuis, com dimensões de $10 x 10 \mathrm{~cm}$ distribuídas conforme o corte do projeto arquitetônico mostrado na figura 2.

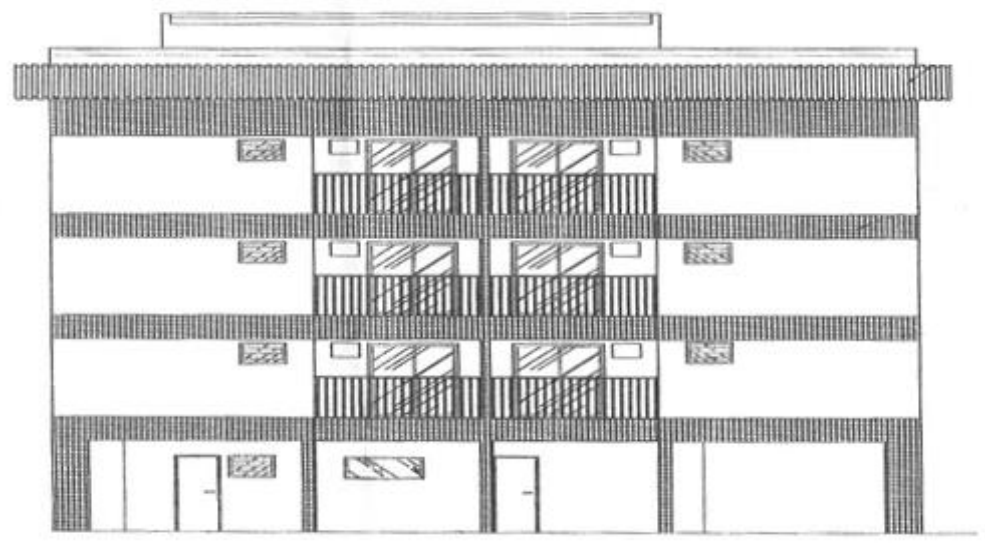

Figura 2: Corte da fachada lateral e entrada da edificação.

Fonte: Projeto para construção de PNR SO/SG- Vila do Marex (2008) 
O projeto da edificação estudada não incluiu projeto específico para a fachada. Além disso, o projeto base para a construção desses blocos residenciais para militares, segue o modelo padrão para todo o Brasil.

\section{RESULTADOS}

\subsection{Inspeção da fachada}

\subsubsection{Fachada Norte}

Pode-se observar que, na figura 3, a placa está afastada da base, o que consiste em descolamento. A figura 4 mostra que houve a perda de uma parte do selante da junta de movimentação, assim como, a queda da placa cerâmica. Bauer et al. (2015) mostram em suas análises que a área de transição entre pavimentos é uma das que mais ocorre a manifestação de patologias por ser uma área de grande movimentação, o que se agrava com a ausência das juntas de movimentação que desempenham a função de absorção dessas tensões solicitantes.

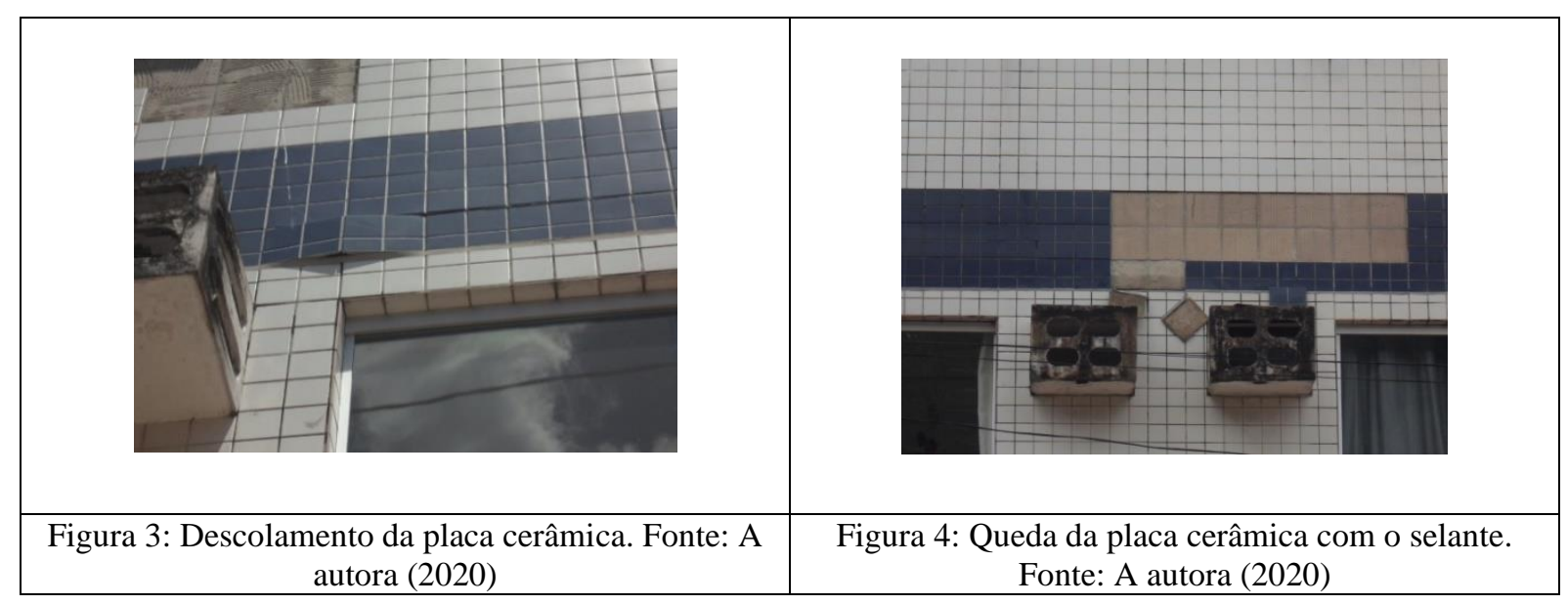

As figuras 5 e 6 mostram o destacamento das placas próximo ao topo e perto da abertura da janela. Manifestações patológicas nessas regiões ocorrem devido grande movimentação do sistema, por serem áreas de descontinuidade (BAUER ET AL., 2015).

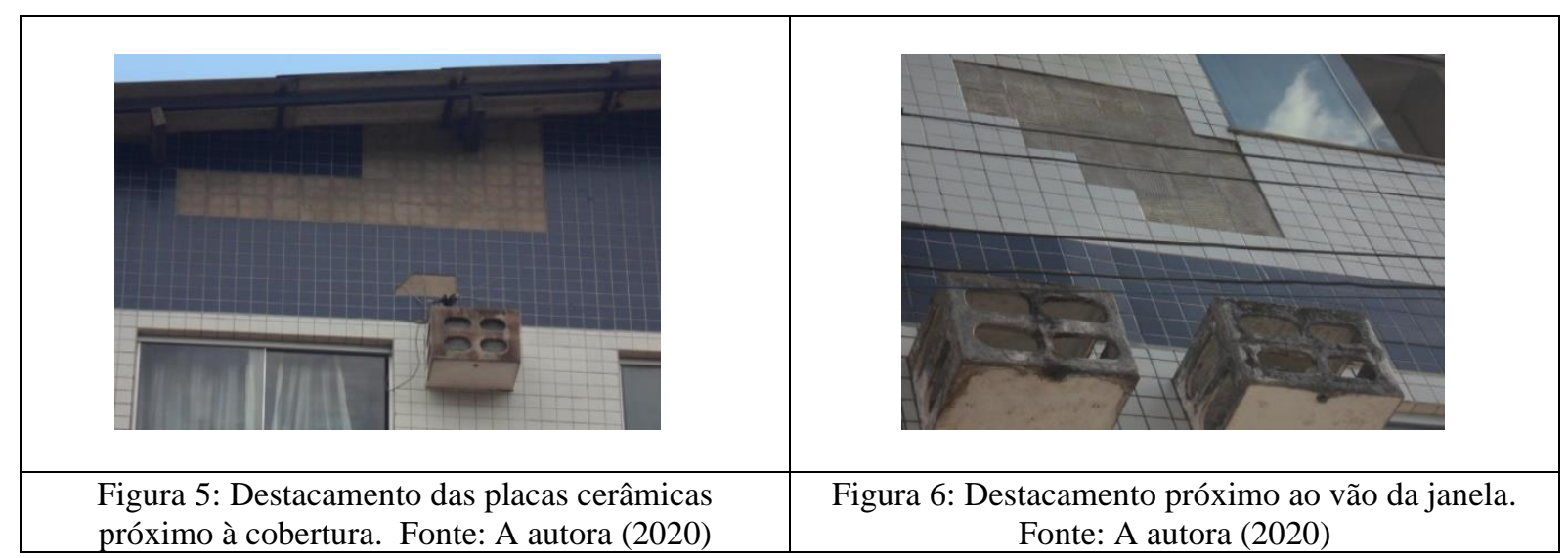


A figura 7 mostra o destacamento se originando na fachada oeste onde há grande deterioração da junta de movimentação e ausência de junta dessolidarização. Em razão disso, não ocorre a dissipação das tensões nessa região, que é uma região crítica por causa da descontinuidade (BAUER ET AL., 2015).

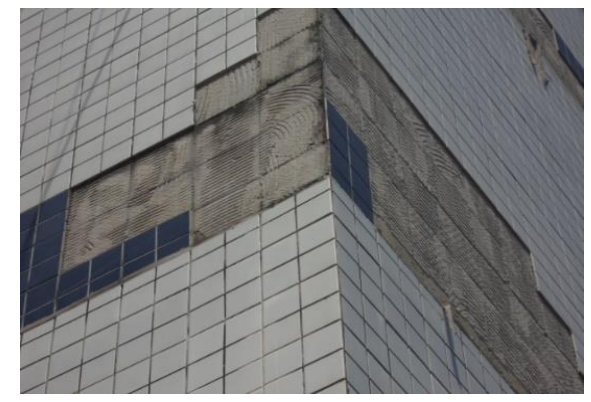

Figura 7: Destacamento das placas cerâmicas. Fonte: A autora (2020)

A figura 8 mostra o rejunte desgastado devido às intempéries (nesse caso, onde não há histórico de lavagem, não se considera o uso de produtos químicos na limpeza como fator degradante). Na figura 9 observa-se uma pequena abertura na junta de movimentação, o que permite a entrada de água, ocasionando assim, infiltrações.

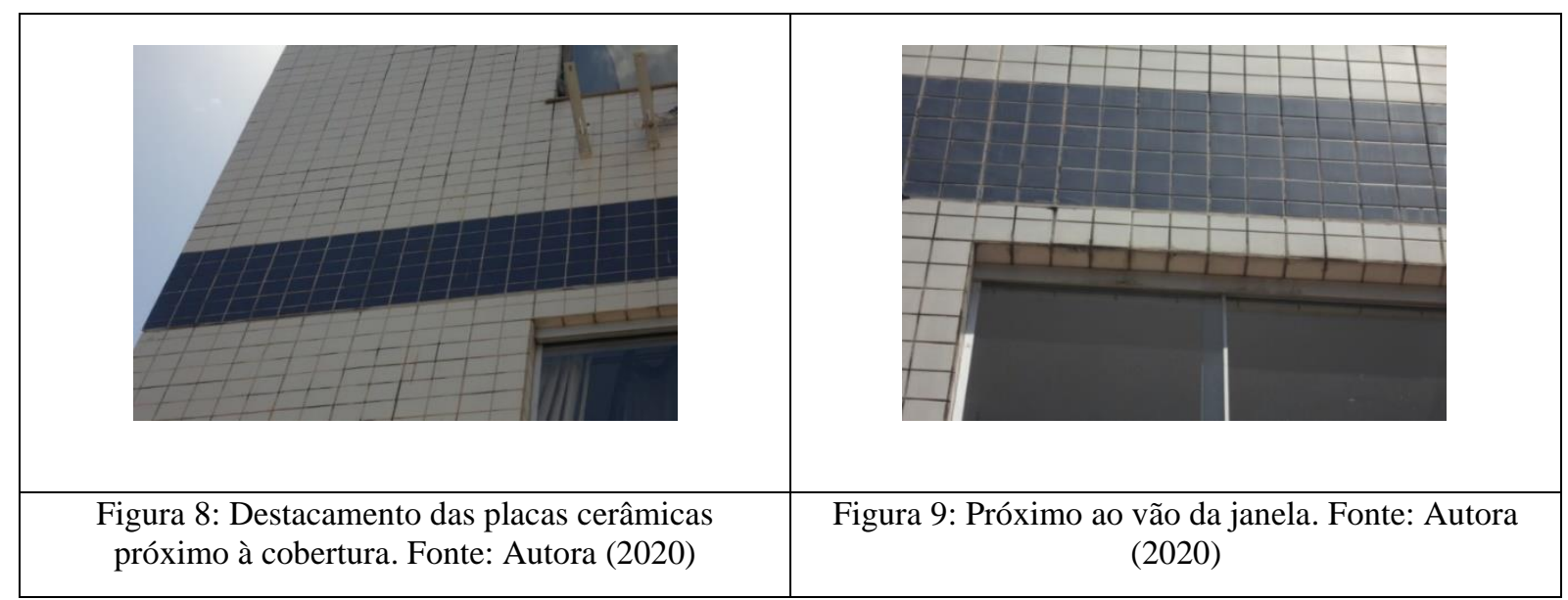

A figura 10 mostra a localização das anomalias no corte de fachada norte, onde o número 1 equivale aos destacamentos das placas cerâmicas e o número 3 ao descolamento.

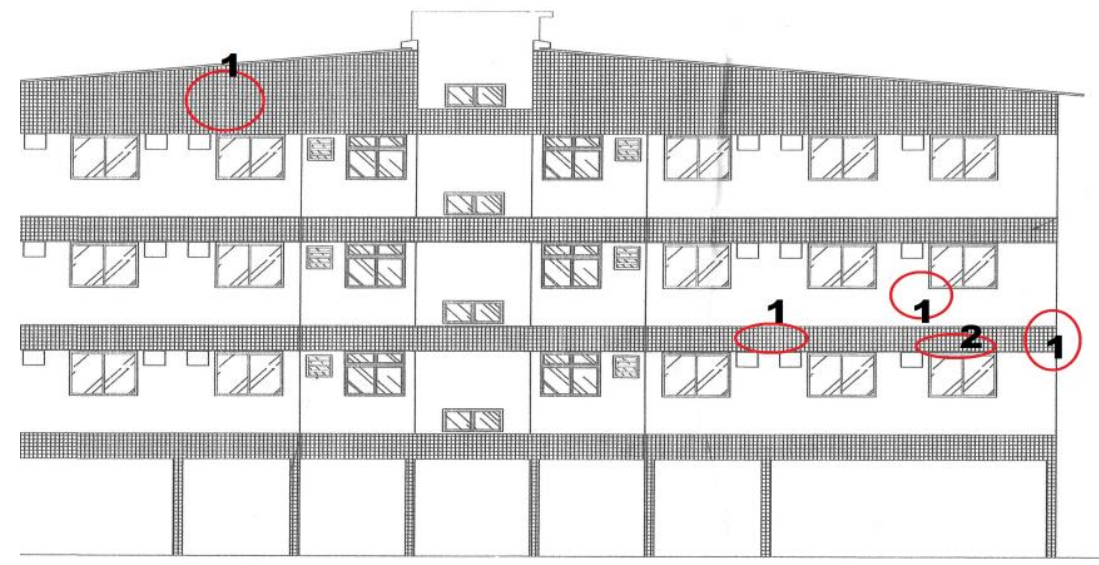

Figura 10: Localização das anomalias no corte da fachada longitudinal da edificação.

Fonte: Projeto para construção de PNR SO/SG- Vila do Marex (2008) 


\subsubsection{Fachada Sul}

A figura 11 apresenta o destacamento se iniciando na aresta da edificação por falta de junta de dessolidarização. Na figura 12, observa-se o manchamento do revestimento cerâmico (eflorescência) devido aos sais dissolvidos e transportados pela água.

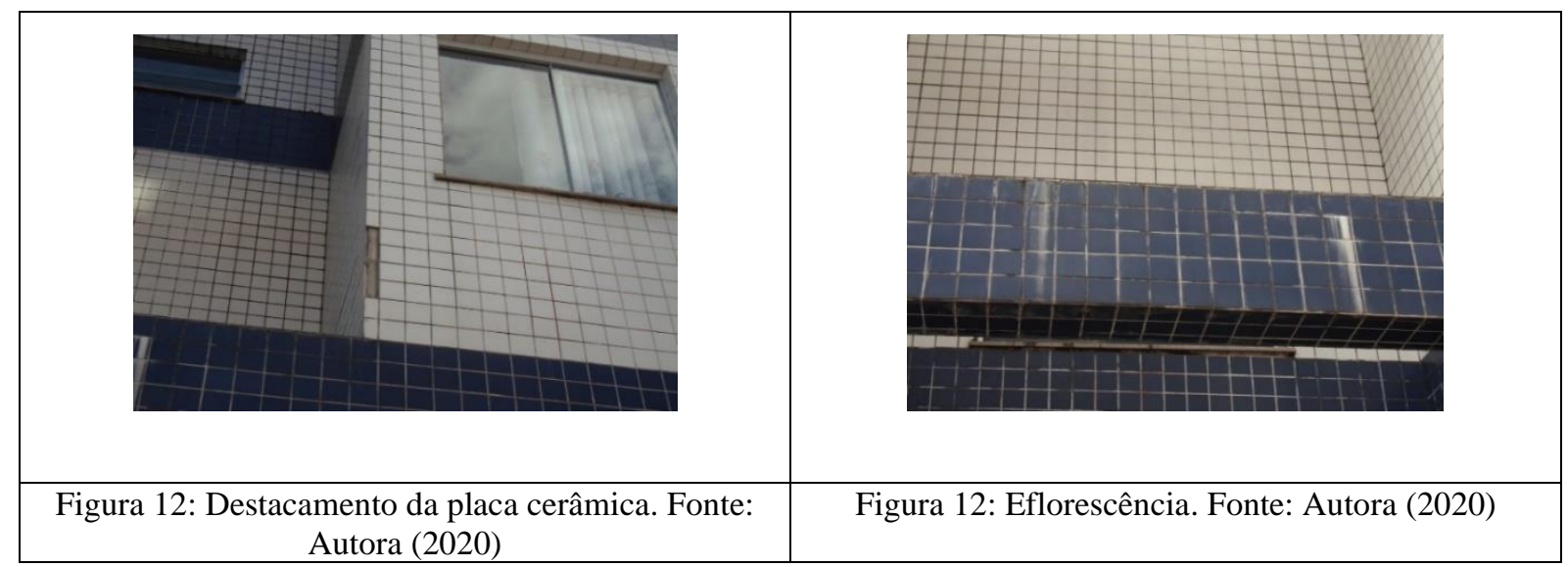

A figura 13 mostra a localização das anomalias no corte da fachada sul, onde o número corresponde ao destacamento da placa cerâmica e o número 3 a eflorescência.

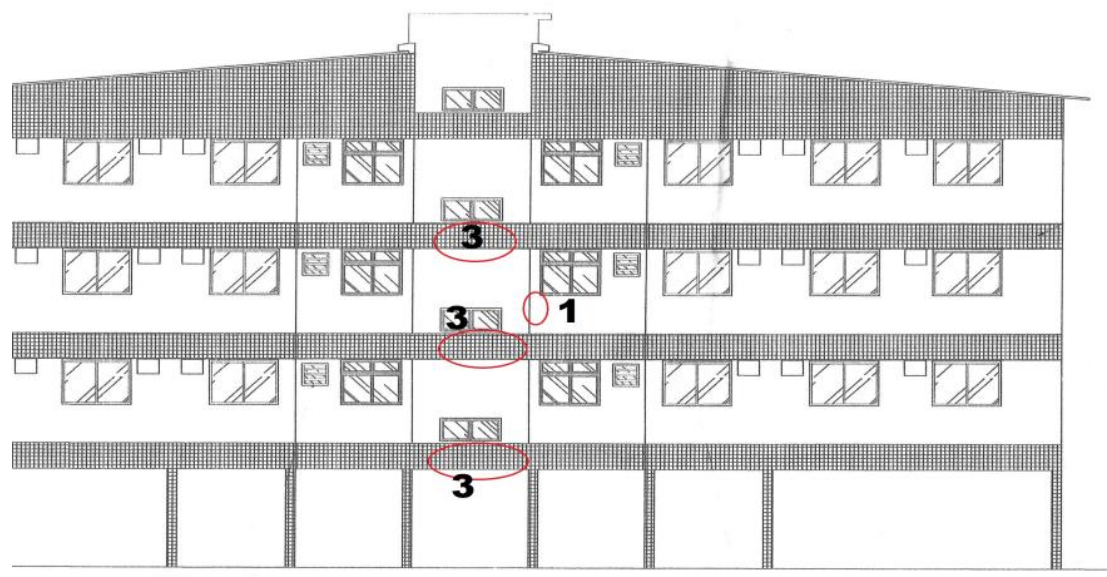

Figura 13: Localização das anomalias no corte da fachada longitudinal da edificação.

Fonte: Projeto para construção de PNR SO/SG- Vila do Marex (2020)

\subsubsection{Fachada Leste}

A figura 14 apresenta as juntas visivelmente deterioradas. É possível observar as fissuras ao decorrer da junta de movimentação e assentamento, o que ocasiona a fácil penetração e escoamento de água pelo sistema.

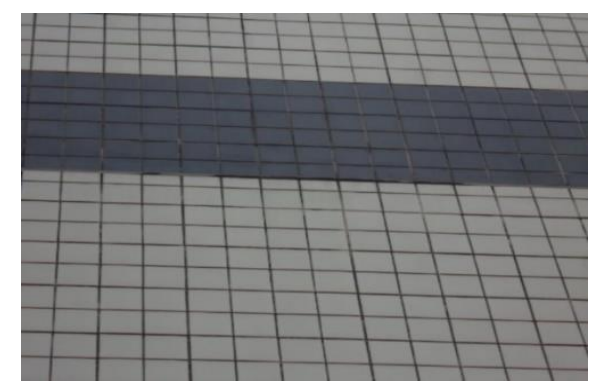

Figura 14: Desgaste das juntas de assentamento. Fonte: Autora (2020) 
As figuras 15 e 16 mostram o destacamento ocorrendo a partir das zonas de maior movimentação, onde estão distribuídas as juntas para absorver esses movimentos. Porém, como essas apresentam elevado grau de deterioração, dáse a perda da aderência nessas áreas.

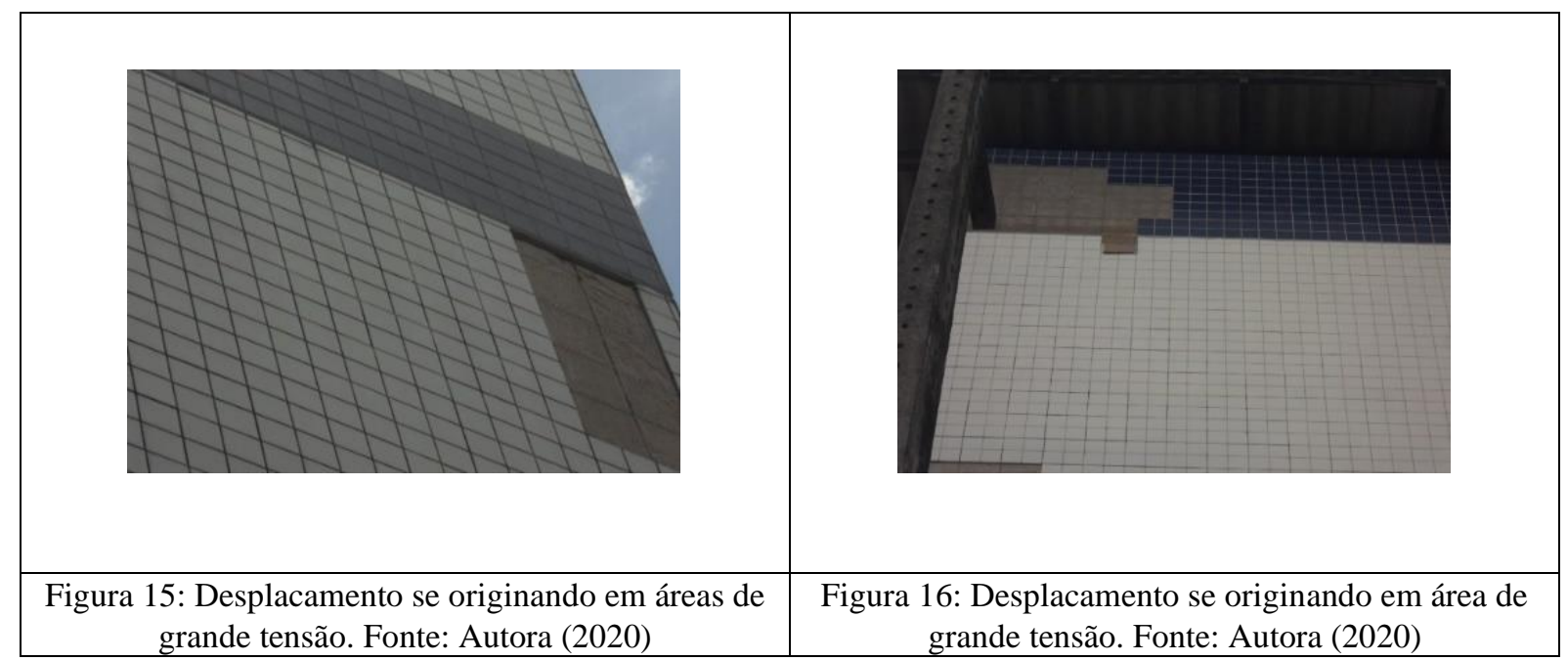

Na figura 17, observa-se os anéis que não foram desfeitos, conforme o procedimento correto de assentamento segundo a NBR 13755:2017, além da cor escura do substrato, provavelmente devido ao excesso de umidade.

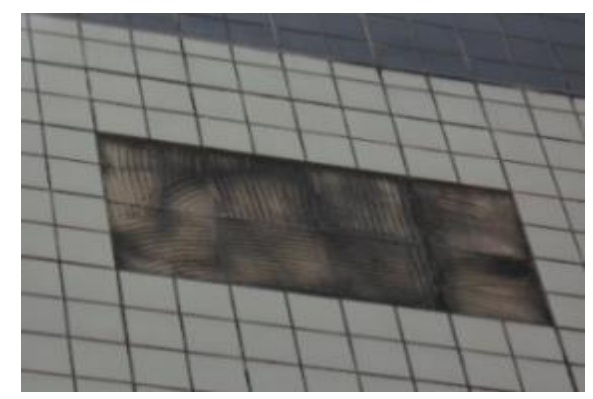

Figura 17. Desplacamento no meio do pano da fachada. Fonte: Autora (2020)

A figura 18 mostra a localização das anomalias no corte da fachada leste, onde o número 1 corresponde ao destacamento das placas cerâmicas.

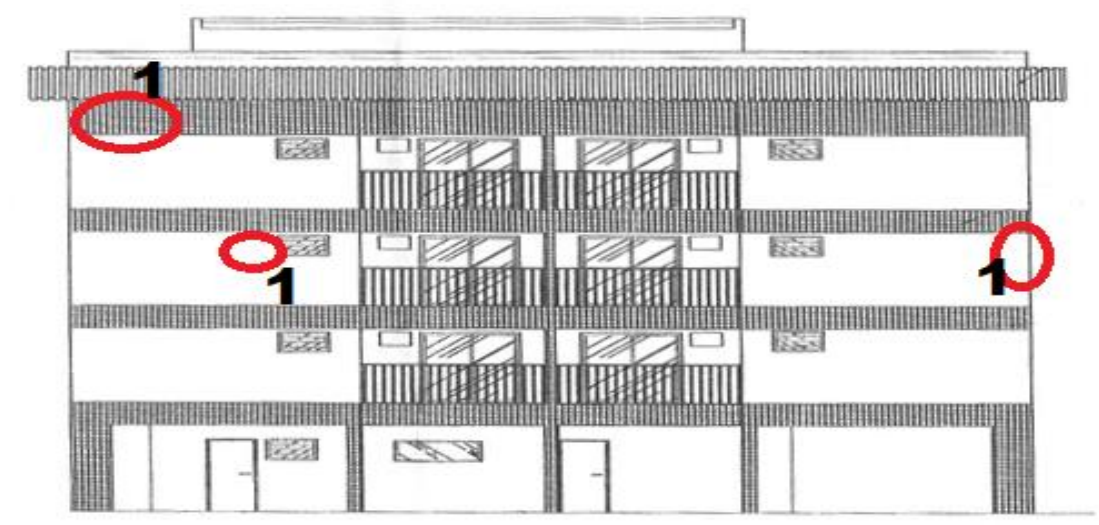

Figura 18: Localização das anomalias no corte da fachada lateral da edificação.

Fonte: Projeto para construção de PNR SO/SG- Vila do Marex (2008) 


\subsubsection{Fachada Oeste}

A fachada oeste foi a que apresentou maior área visível de deterioração. Bauer et al. (2015) relacionam esse fenômeno ao nível de exposição solar das fachadas.

Nota-se, nas figuras 19 e 20, o efeito da deterioração das juntas de movimentação sobre o descolamento das placas. Observa-se que o houve a perca do selante, o que levou à queda do mastique e destacamento das placas cerâmicas.

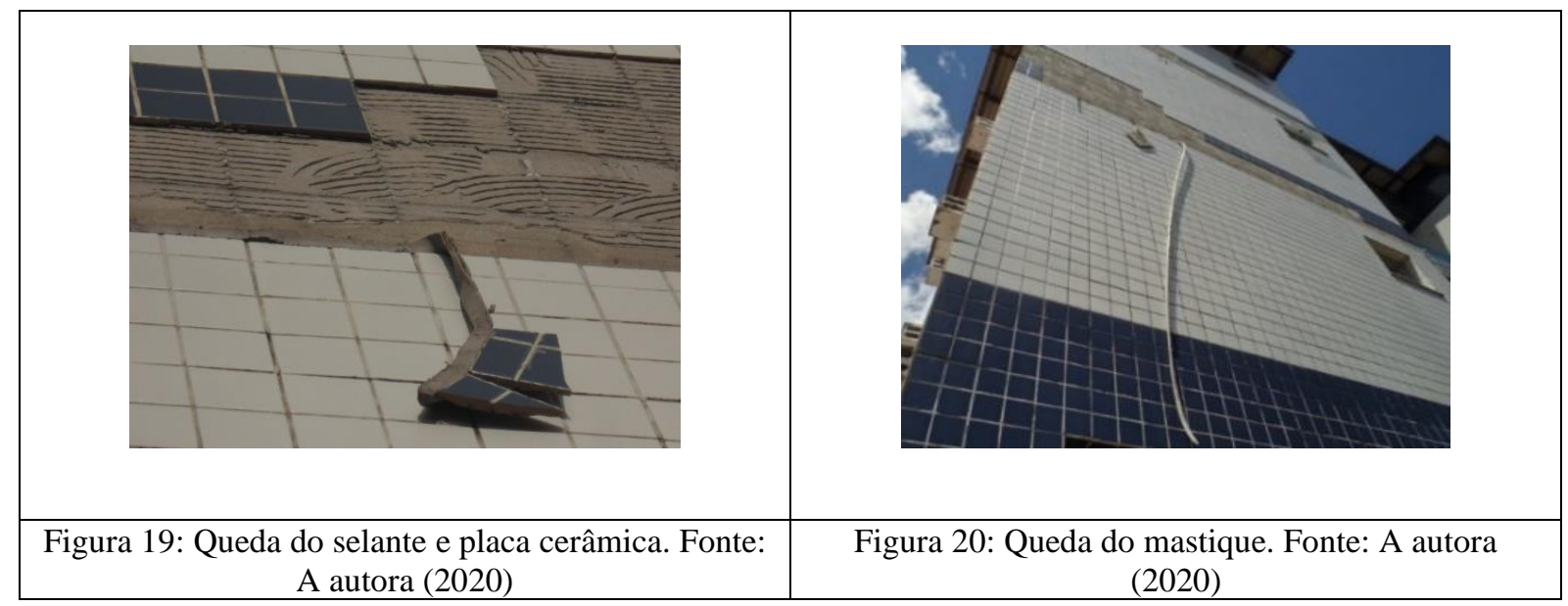

A figura 21 mostra a localização das anomalias no corte da fachada oeste, onde o numero 1 corresponde ao destacamento das placas cerâmicas e o número 2 a deterioração das juntas de movimentação.

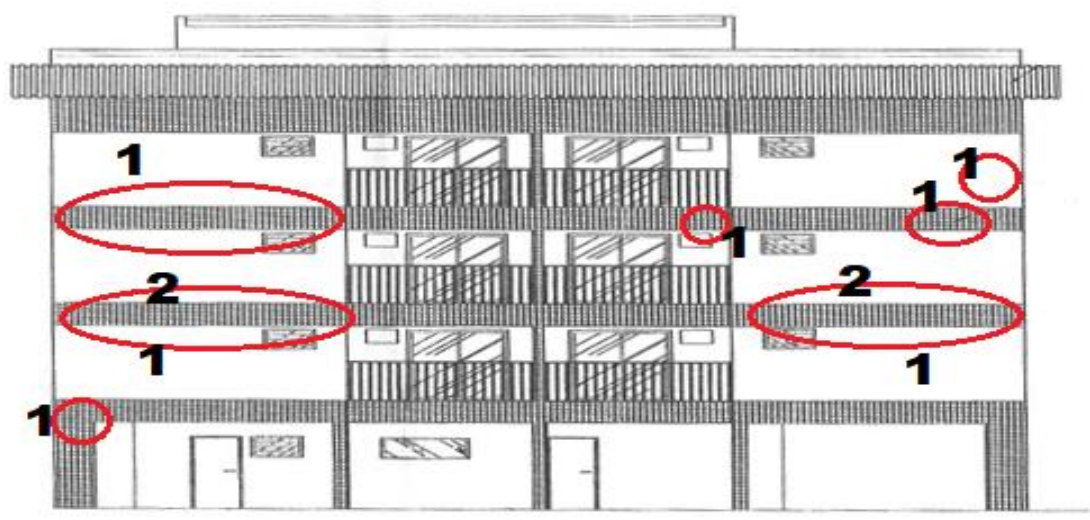

Figura 21: Localização das anomalias no corte da fachada lateral da edificação. Fonte: Projeto para construção de PNR SO/SG- Vila do Marex (2008)

\subsection{Inspeção interna}

\subsubsection{Inspeção visual e análise dos pontos de umidade com a câmera térmica}

$\mathrm{Na}$ inspeção interna, foram analisados apenas os pontos com fachada do outro lado, ou seja, foram excluídas as paredes apenas com função de divisão interna. Para esta análise, foi escolhido um apartamento com fachada ao norte da edificação, onde há grande influência da luz do sol na maior parte do dia.

A figura (c) é a análise visual do interior da edificação, onde não é possível observar claramente os pontos de umidade, porém ao tocar a parede, a sensação de frio devido a água infiltrada é perceptível. As imagens (a) e (b) seriam a justificativa para essa patologia interna, onde há a abertura na junta de movimentação (a) e, consequentemente, o descolamento da placa cerâmica em (b), facilitando a infiltração da água para o interior do apartamento. Na figura (d), 
por meio da análise termográfica da imagem da câmera FLIR e com auxílio do software FLIR Tools, foi possível determinar a temperatura dos diferentes pontos no termograma, representados por Sp1, Sp2 e Sp3, onde notou-se pouca variação térmica entre eles. É necessário salientar que alguns parâmetros necessários para análise quantitativava, por termografia, segundo Silva (2012) não foram considerados, como umidade relativa do ar e emissividade do material, tornando a avaliação termográfica, apesar dos dados sobre temperatura, apenas qualitativa.

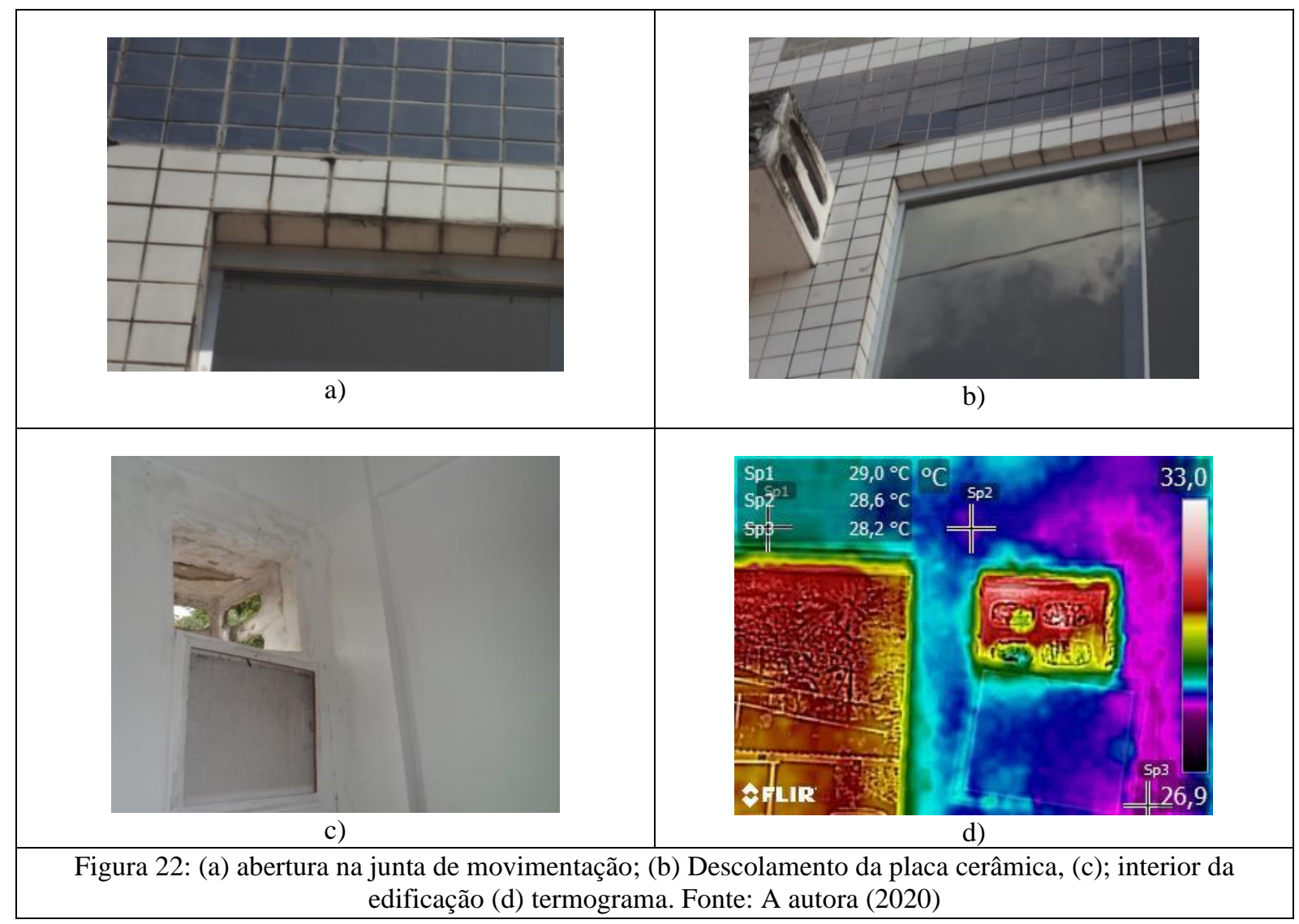

No segundo cômodo há penetração da água devido ao desplacamento do revestimento externo. Nesse termograma há uma maior disparidade de temperatura entre os pontos, provavelmente pelo fato de já ter ocorrido o desplacamento nessa área. Entretanto, não é possível a análise quantitativa por falta dos parâmetros umidade relativa do ar e emissividade do material.

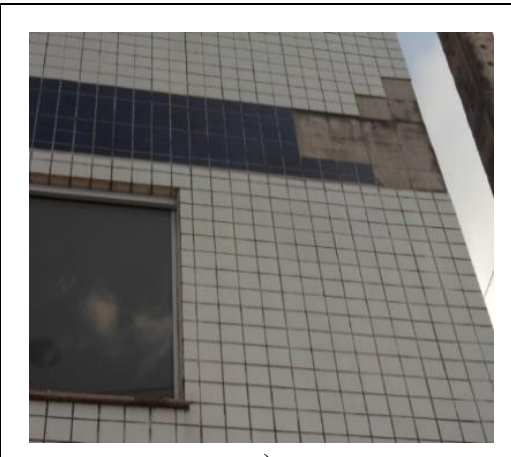

a)

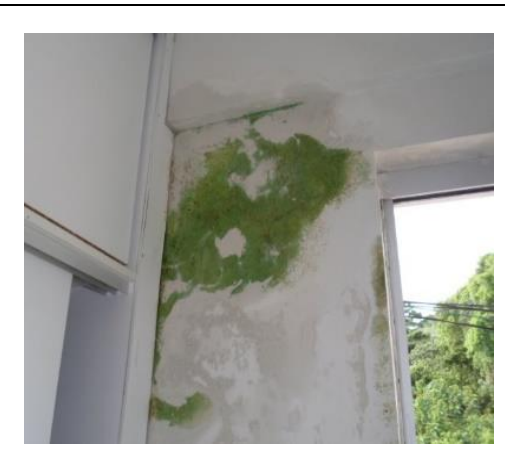

b)

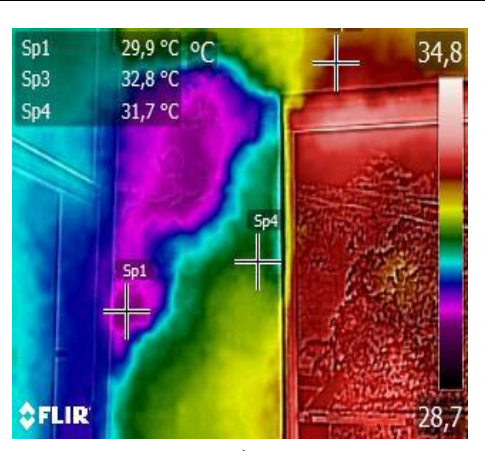

c)

Figura 23: (a) abertura na junta de movimentação; (b) Descolamento da placa cerâmica, (c); interior da edificação (d) termograma. Fonte: Autora (2020)

Os outros cômodos não apresentaram infiltrações perceptíveis ao toque e à olho nu, pois suas paredes internas eram de revestimento cerâmico. 


\section{CONCLUSÃO}

A partir da inspeção realizada foi possível detectar diferentes anomalias em todos os panos de fachada.

A fachada Oeste apresentou maior área de manifestação patológica, a fachada sul, a menor. Isso ocorreu devido ao grau de exposição solar de cada uma delas.

Em todos os panos da fachada estudada, a manifestação patológica predominante foi o destacamento das placas cerâmicas, que teve como principal causa visível a deterioração das juntas. É importante frisar que não houve realização de ensaios da argamassa ou das placas cerâmicas, sendo a avaliação da fachada completamente visual.

O apartamento usado como modelo para avaliação dos efeitos das anomalias na área interna da edificação apresentou excessiva umidade (grande área) em pontos que coincidiram com as patologias externas. Ou seja, os desplacamentos e deterioração das juntas na fachada norte, onde se localizava a vedação externa do apartamento avaliado, afetaram consideravelmente o interior da edificação, o que comprova o elevado estado de degradação da fachada. Portanto, subtende-se que as paredes internas onde não foram encontrados pontos de infiltrações visíveis, têm grande possibilidade de estarem comprometidas devido a intensidade das infiltrações encontradas nos outros pontos.

A análise termográfica permitiu a avaliação qualitativa das manifestações patológicas, ou seja, a localidade das infiltrações no interior da edificação. Não foi possível a análise quantitativa por falta de dois parâmetros importantes como emissividade do material analisado e umidade relativa do ar, que em Belém é extremamente alta, o que influencia diretamente nessa avaliação.

Diante da avaliação realizada, conclui-se que, a falta de projeto específico considerando as individualidades climatológicas de Belém, visto que, o projeto base para a construção desse modelo de bloco de apartamentos para militares seguem o mesmo modelo para todo o Brasil, além da falta de manutenção preventiva, contribuiu diretamente para o surgimento das anomalias presentes em todos os panos de fachada do bloco estudado, onde, mesmo com alguns anos de utilização, segundo relato de moradores e responsáveis, apresentou intensa deterioração, assim como, o interior dos apartamentos, prejudicando além da segurança dos moradores, devido aos desplacamentos recorrentes da fachada, o conforto e saúde, devido a umidade provocada pelas infiltrações decorrentes dessas anomalias.

\section{REFERÊNCIAS}

Associação Brasileira de Normas Técnicas. Revestimento de paredes externas e fachadas com placas cerâmicas e com utilização de argamassa colante; Procedimentos - NBR 13755. Rio de Janeiro, 2017.

ANTUNES, G. R. Estudo de Manifestações Patológicas em Revestimentos de Fachada em Brasília Sistematização da Incidência de Casos. Dissertação de Mestrado. Universidade de Brasília. Distrito Federal. 2010.166 p.

BALARAS, C. A ; ARGIRIOU, A. A. Infrared thermography for building diagnostics. Energy and Buildings, Lausanne, v. 34, n.2, p. 171-183, 2002.

BAUER, E.; CASTRO, E. K.; SILVA, M. N. B. Estimativa da degradação de fachadas com revestimento cerâmico: estudo de caso de edifícios de Brasília. Revista Cerâmica, São Paulo, v. 61, p.151-159, 2015.

BAUER, E; SILVA, M.N.B.; ZANONI, V.A.G. Mensuração da degradação e vida útil em fachadas. In: XI SBTA Simpósio Brasileiro de Tecnologia das Argamassas. Anais ... ANTAC: Porto Alegre, 2015.

CARVALHO, C.L.D. Estudos das patologias da fachada de edíficio residencial em Aracaju. Monografia (Graduação)- Curso de Engenharia Civil, Instituto federal de Sergipe, Aracaju, 2017.

CHAVES, A.M.V.A.. Patologia e Reabilitação de Revestimentos de Fachadas. 160 f. Dissertação (Mestrado) Curso de Engenharia Civil, Universidade do Moinho, Valpaços, 2009. 
CORTIZO E. C.; BARBOSA, M. P.; SOUZA, L. A. C. Estado da arte da termografia. Fórum Patrimônio: Ambiente Construído e Patrimônio Sustentável, Belo Horizonte, v. 2, n. 2, p. 1 58-1 93, 2008.

CORTIZO, E. C. Avaliação da Técnica de Termografia Infravermelha Para Identificação de Estruturas Ocultas e Diagnóstico de Anomalias em Edificações: ênfase em edificações do patrimônio histórico. Belo Horizonte, 2007. 177 f. Tese (Doutorado em Engenharia Mecânica) - Escola de Engenharia, Universidade Federal de Minas Gerais, Belo Horizonte, 2007.

FLIR Systems, Inc. FLIR C2. América Latina, Sorocaba - SP, $2014 . \quad$ Disponível em: <https://www.flirmedia.com/MMC/THG/Brochures/BLD_008/BLD_008_PT.pdf>.Acesso em: 18/11/19.

LOPES, C. A. S. Durabilidade na construção: estimativa da vida útil de revestimentos cerâmicos de fachadas. Dissertação (Mestrado em Construções Civis). Universidade do Porto, Porto, 2009.

MEDEIROS, J. S.; SABBATINI, F. H. Tecnologia e projeto de revestimentos cerâmicos de fachadas de edifícios. Boletim Técnico: BT/PCC/246. São Paulo: EPUSP, 1999, 28p.

RIBEIRO, F. A.; BARROS, M. M. S. B. Juntas de Movimentação em Revestimentos Cerâmicos de Fachadas. São Paulo: PINI, 2010.

ROSCOE, M. T. (2008). Patologias em revestimento cerâmico de fachada. Universidade Federal de Minas GeraisCurso de Especialização em Construção Civil-CECC. Minas Gerais.

PACHECO, C. P.; VIEIRA, G. L. Análise Quantitativa da Degradação das Fachadas com Revestimento Cerâmico. Cerâmica, São Paulo, v. 63, n. 368, p. 432-445, out.-dez. 2017.

PEDRO, E. G.; MAIA, L. E. F. C. ; ROCHA, M. O.; CHAVES, M. V. . Patologia em Revestimento Cerâmico de Fachada. Curso de Pós-Graduação do CECON, Especialização em Engenharia de Avaliações e Perícias. Síntese de Monografia. Belo Horizonte, 2002.

SILVA, D. D. S. Diagnóstico de patologias em fachadas utilizando termografia. Dissertação de mestrado em Engenharia Civil. Faculdade de Engenharia, Universidade do Porto, Porto, 2012.

TERRA, R. C. Levantamento de manifestações patológicas em revestimentos de fachadas das edificações da cidade de Pelotas. Dissertação de mestrado. Programa de Pós-Graduação em Engenharia Civil da Universidade Federal do Rio Grande do Sul, Porto Alegre, 2001.

The Weather Channel. Disponível em: <http://br.weather.com/weather/climatology/BRxx1479.> Acesso em 20/09/2019 